\title{
Folk Intuitions about the Causal Theory of Perception
}

\author{
PENDARAN ROBERTS \\ Department of Philosophy, University of Warwick \\ KEITH ALLEN \\ Department of Philosophy, University of York \\ KELLY SCHMIDTKE \\ Warwick Business School, University of Warwick
}

\begin{abstract}
It is widely held by philosophers not only that there is a causal condition on perception but also that the causal condition is a conceptual truth about perception. One influential line of argument for this claim is based on intuitive responses to a style of thought experiment popularized by Grice. Given the significance of these thought experiments to the literature, it is important to see whether the folk in fact respond to these cases in the way that philosophers assume they should. We test folk intuitions regarding the causal theory of perception by asking our participants to what extent they agree that they would 'see' an object in various Gricean scenarios. We find that the intuitions of the folk do not strongly support the causal condition; they at most strongly support a 'no blocker' condition. We argue that this is problematic for the claim that the causal condition is a conceptual truth.
\end{abstract}

\section{Introduction}

Many philosophers claim that it is a conceptual truth about perception that veridical perceptual experiences are caused by the objects that they are experiences of. For instance, the following three statements constitute a version of the Causal Theory of Perception defended by Grice (1961):

Contact: Pendaran Roberts <Pendaran@mac.com>, Keith Allen <keith.allen@york.ac.uk>, Kelly Schmidtke, <Kelly.Schmidtke@wbs.ac.uk> 
1. Necessarily, if a subject sees an object, that object causally affects the subject.

2. Necessarily, if a subject sees an object, that object produces in the subject a state reportable by a sentence beginning, 'It looks to me as if . . '

3. 1 and 2 are conceptual truths.

Along similar lines, Strawson says the following:

[The] notion of the causal dependence of the experience enjoyed in senseperception on features of the objective spatio-temporal world is implicit from the very start in the notion of sense-perception, given that the latter is thought of as generally issuing in true judgements about the world. It is not something we discover with the advance of science, or even by refined philosophical argument .... Hence any philosophical theory which seeks to be faithful to our general framework of ideas, our general system of thought, must provide for this general notion of causal dependence. It must, to this extent at least, be a causal theory of perception. (1992: 61; see also 1979: 51)

Building on Grice's ideas, Lewis (1980) combines the causal theory of perception with a reductive counterfactual theory of causation. He argues that for an experience to count as a case of perception, the experience must counterfactually depend in the appropriate way upon the scene. More recently, the claim that it is a conceptual truth that there is a causal condition on perception has featured prominently in influential discussions on the metaphysics of color. Johnston (1992) proposes five core beliefs about color, where a core belief about color is a belief central to the concept of color. One of these five core beliefs, called 'Explanation,' may be seen to imply a causal condition on color perception:

The fact of a surface or volume or radiant source being canary yellow sometimes causally explains our visual experience as of canary yellow things. (Johnston 1992: 222)

Similarly, Jackson claims that it is a "conceptual truth about presentation" that "the property of objects putatively presented to subjects when the objects look [for example] yellow is at least a normal cause of their looking yellow" (1998: 93). He argues from this putative conceptual truth to the conclusion that colors are microphysical properties of objects, since physics suggests that it is these properties that cause color experiences. ${ }^{1}$

1. There are different forms of the causal theory of perception which are supposed to reflect different supposed 'deep facts' about how we understand perception, for instance: whether ex- 
Why is it a commonly held belief that it is a conceptual truth that there is a causal condition on perception? Probably the best known argument appeals to our intuitions (or judgments) regarding a kind of thought experiment popularized by Grice (1961). ${ }^{2}$ The standard Gricean arguments go like this: We are asked to imagine that a subject has a perceptual experience as of an object in front of them, and that the object in front of them is exactly as it is perceived to be. It is then claimed (at least implicitly) that it is intuitive that the subject fails to see the object in front of them. Here is an example of a standard Gricean argument:

Suppose it looks to $X$ as if there is a clock on the shelf; what more is required for it to be true to say that $X$ sees a clock on the shelf? There must, one might say, actually be a clock on the shelf which is in X's field of view, before $X^{\prime}$ s eyes. But this does not seem to be enough. For it is logically possible that there should be some method by which an expert could make it look to $X$ as if there were a clock on the shelf on occasions when the shelf is empty: there might be some apparatus by which X's cortex could be suitably stimulated, or some technique analogous to post-hypnotic suggestion. If such a treatment were applied to $X$ on occasion when there actually was a clock on the shelf, and if X's impressions were found to continue unchanged when the clock was removed or position altered then I think we should be inclined to say that $X$ did not see the clock which was before his eyes, just because we should regard the clock as playing no part in the origination of his impression. (Grice 1961: 69)

Here is another example:

It might be that it looked to me as if there were a certain sort of pillar in a certain direction at a certain distance, and there might actually be such a pillar in that place; but if, unknown to me, there were a mirror interposed between me and the pillar, which reflected a numerically different though similar pillar, it would certainly be incorrect to say that I saw the first pillar, and correct to say that I saw the second. (Grice 1961: 69-70)

periences need to be reportable using sentences beginning 'It seems to me as if . . .;' whether the conceptual claim is restricted to experiences produced via 'standard causal processes' (e.g., Grice 1961; cf. Lewis 1980); whether the causal theory involves a commitment to some form of sensedatum theory (e.g., Grice 1961) or is combined with a form of the representationalist theory of perception (e.g., Strawson 1992; Lewis 1980; Jackson 1998). Nevertheless, the core commitment of all these views is that it is a conceptual truth about perception that veridical perceptual experiences are caused by the objects in the environment that they represent. We shall focus on this core commitment in this paper.

2. We are not presupposing any particular account of the nature of intuitions. They do not, for instance, need to be non-inferential or non-deliberative. Intuitions could just be judgments, and to say that ' $x$ is intuitive' might just be to say that 'we are inclined to judge that $x$. '

Ergo vol. 3, no. 28 • 2016 
The standard diagnosis of why we are not intuitively prepared to ascribe perception in Gricean cases (e.g., the clock and pillar cases above) is that there is no causal connection between the object and the subject's experience. So, as the standard diagnosis goes, the existence of a causal connection between the object and the experience is (in some sense or another to be discussed later) conceptually necessary for an experience to count as veridical.

The Gricean style of argument for the conceptual requirement of a causal condition on perception is not uncontroversial. Typically, however, those who oppose the conceptual requirement of a causal condition on perception do not deny the intuitive verdicts that Gricean cases are claimed by their proponents to elicit. Rather, what they normally dispute is whether Gricean cases are sufficient to establish that it is a conceptual truth about perception that our perceptual experiences are causally dependent on the way the world is, rather than dependent on the world in some other, non-causal way (White 1961; Hyman 1992; Roessler 2011; for further discussion, see Allen, 2016: Chapter 5).

Whether the intuitive verdicts that Gricean cases are claimed to elicit are really intuitive is a question that experimental philosophy can contribute to. To date, comparatively little work in experimental philosophy has been done on the philosophy of perception. ${ }^{3}$ However, the results of one study suggest that philosophers' intuitions about the causal condition may not match those of the folk. Roberts and Schmidtke (2016) tested Johnston's (1992) core beliefs about color to see whether they are agreed with by the folk. They found that although the core beliefs Johnston lists were all widely accepted, the least widely accepted was Explanation. This suggests that the folk do not strongly endorse the idea that the colors cause our experiences of them, and so might suggest that the folk do not strongly endorse a causal condition on perception more generally. The present empirical study investigates the causal condition further by specifically looking at folk intuitions regarding Gricean cases.

We test folk intuitions using two kinds of cases: blocker and non-blocker cases. These are the kinds of cases normally presented in support of the causal condition. Blocker cases involve a physical object that blocks the subject's line of sight of the object. The physical blocker interferes with the causal processes involved in perception just by being in the way. Grice's pillar case is a blocker case. Non-blocker cases involve interference with the causal processes involved in perception too, but, unlike blocker cases, this interference

3. One of the first studies in the area was by Cohen and Nichols (2010). They used experimental techniques to argue that our intuitions do not clearly support non-relational views of color. For responses to Cohen and Nichols' study, see Roberts, Andow, and Schmidtke (2014) and Roberts and Schmidtke (2016). A different issue is explored by Fischer and Engelhardt (2016), who provide a psycholinguistic debunking explanation of the intuitions appealed to in presentations of the argument from illusion. 
is not caused by a physical blocker. Grice's clock case is a non-blocker case. Grice proposes, in the clock case, that the interference could be caused by brain stimulation or hypnosis. As both blocker and non-blocker cases interfere with the causal processes involved in perception, if folk intuitions accord with the causal condition, the folk should agree that no seeing occurs in both types of cases.

Although intuitions about the blocker and non-blocker cases are the main focus of our study, we also test intuitions regarding the counterfactual dependence of experience on the world. It is natural to think that a counterfactual dependence of the subject's experience on the world is implied by the causal condition (if A causes B, then if A were removed, B would not occur). ${ }^{4}$ If the causal condition implies a counterfactual dependence, then the folk should agree that no seeing occurs when there is no counterfactual dependence. Grice's quoted clock case explicitly states that there is no counterfactual dependence, but the quoted pillar case does not. Mirroring this, we made it explicit that there is no counterfactual dependence in only some of our cases.

\section{The Experiment}

Participants. In total, 140 participants completed the survey via the University of Warwick's sona-system. Students at the University of Warwick are actively recruited to join the sona-system. Faculty who wish to join are able to do so, but the primary participant pool is university students. Seven participants were excluded, because they had formal training in philosophy (6 were currently enrolled in a philosophy program, and 1 had earned a BA in philosophy). A further 65 participants were excluded for answering one or more comprehension questions incorrectly. Of the remaining 68 participants, 47 identified as female, 65 identified as current students, 2 identified as not being current students, and 1 did not identify their student status. The median age of the 68 participants was 21 years $(S D=5.57)$. Participants were asked to type in what their native language was. The responses to the six biggest language groups were as follows: 38 participants typed in 'English,' 6 'Chinese,' 5 'Malay,' 4 'Spanish,' 2 'German,' and finally 2 'Portuguese.'

4. Consider, for example, Woodward's characterization of broadly 'difference-making' theories of causation, according to which "the presence of the cause makes a difference to the effect in the sense that in a situation in which the cause is appropriately different, the effect will or would be different" (2011: 232).

The idea that a counterfactual dependence is implied by the causal condition should not be confused with Lewis's (1980) idea that the causal condition can be reduced to a condition involving counterfactual dependence. 
Materials. The survey was created and administered using Qualtrics, Version 2015. The data was analyzed with IBM SPSS, Version 22.

Procedure. Consenting participants were presented with a practice case before considering the six cases of interest in a random order. Each case was presented over three screens. The initial screen presented just the case. For example, in the practice case, the initial screen read: 'You are currently taking a survey online. You should read each case carefully before advancing to the 4 questions about it. This is only a practice case.' To advance, the participants clicked the advance button. The second screen included the case at the top followed by three comprehension items. The comprehension items were three statements, and participants were asked to say for each statement whether it was true or false. For every case, one comprehension item was false. For the practice case, the comprehension items were the following: 'This is a practice case;' 'You should read each

Table 1.

\begin{tabular}{lll}
\hline & Blocker & Non-blocker \\
Explicit & Dog & Clock \\
Non-explicit & Pillar & Snake
\end{tabular}

case carefully;' and 'You will be asked 1o questions about each case.' The third screen included the case at the top and the target question below: 'On a scale from I (disagree strongly) to 1o (agree strongly), how much do you agree with the statement: "I feel ready to proceed to the remaining cases.".'

The six cases of philosophical interest were presented following the same pattern as the practice case. Four cases were designed to create a two-by-two factorial with blocker as one factor and explicit as the other (see Table 1).

Two of the cases were blocker cases (Pillar and Dog) and two were nonblocker cases (Clock and Snake). Blocker cases involve something literally in the way of one's vision, and non-blocker cases do not. Two of the cases made it explicit that there was no counterfactual dependence (Dog and Clock) and two did not (Pillar and Snake). We thought adding the complication to only some of our cases allowed us to examine a trade-off between precision and brevity. We were concerned about our cases being too long and so perhaps too hard to understand for our participants; however, we were also concerned about the cases not being clear. We wanted to anticipate both types of concerns so we would be better able to respond to them. Additionally, we included one case we presumed participants would not agree with (Elephant) and another case we presumed they would agree with (Tomato). The cases used can be seen in Table 2.

Let us explicitly state how the study worked for the six cases of philosophical interest. The first screen presented the case. The second screen presented the 
Table 2

\begin{tabular}{ll}
\hline Dog & It looks to you as if there is a black dog in front of you. There is a black dog in \\
front of you. But you are wearing a virtual reality headset that is presenting an \\
image being recorded of an exactly similar dog which is behind you. Due to the \\
virtual reality headset, it would look to you as if there were a black dog in front of \\
you even if the actual dog in front of you walked away. \\
It looks to you as if there is a pillar in front of you. There is a pillar in front of you \\
(Pillar 1). But unbeknownst to you, there is a mirror between you and it, which is \\
reflecting a different pillar (Pillar 2) that is the same in every respect to Pillar 1. \\
A scientist is stimulating your brain so that it looks to you as if there is a clock in \\
front of you. As it happens, there really is a clock in front of you that matches ex- \\
actly how things look, but the scientist would make it look to you as if there were \\
a clock even if there were not one. \\
You have taken a drug that effects your brain so that it looks as if there is a snake \\
in front of you. As it happens, there really is a snake in front of you that looks \\
exactly that way. \\
Nothing weird is going on. You are looking at a tomato directly in front of you, \\
Tomato $\quad \begin{array}{l}\text { and so, as is normal, you visually experience the tomato as being directly in front } \\
\text { of you. }\end{array}$ \\
You are looking at a tomato directly in front of you, but because of a drug you \\
visually experience an elephant instead.
\end{tabular}

three comprehension questions (one of which was always false). The third screen presented the chief question of interest, 'On a scale from I (disagree strongly) to 10 (agree strongly), how much do you agree with the statement: "You see the ...";' in the Snake case, for example, the statement in question read: 'You see the actual snake.' The procedure as described so far can be seen in Appendix A, where we have included screen captures of the survey.

After responding to all six cases, participants were asked about their gender, age, whether they had any formal training in philosophy, to type in the name of their native language, and to tell us about any additional concerns. Finally, they were told to enter their email address to be considered for the lottery draw. Typically, participants completed the survey in about six and a half minutes ( $M d n=$ 388.5 seconds, $\mathrm{IQR}=327-552$ seconds).

Results. Participants disagreed with the Pillar case the most $(M=2.1, M d n=$ 1.0, Mode =1.0, $S D=2.2)$, followed by $\operatorname{Dog}(M=2.4, M d n=1.0$, Mode $=1.0, S D=$ 2.1), Elephant $(M=2.6, M d n=1.5, M o d e=1.0, S D=2.4)$, Clock $(M=4.4, M d n=4.0$, Mode = 1.0, $S D=3.2)$, Snake $(M=4.7, M d n=4.0, M o d e=1.0, S D=3.4)$, and finally Tomato $(M=9.4, M d n=10.0, M o d e=10.0, S D=1.9)$. For each case, the percent who selected each response option (1-10) is displayed in Figure 1. For Pillar, approximately $67 \%$ responded 1 , so most of the bar is the darkest black color; while for Tomato, approximately $80 \%$ responded 10, so most of the bar is the lightest grey color. The remaining cases are between these two descriptively speaking. 


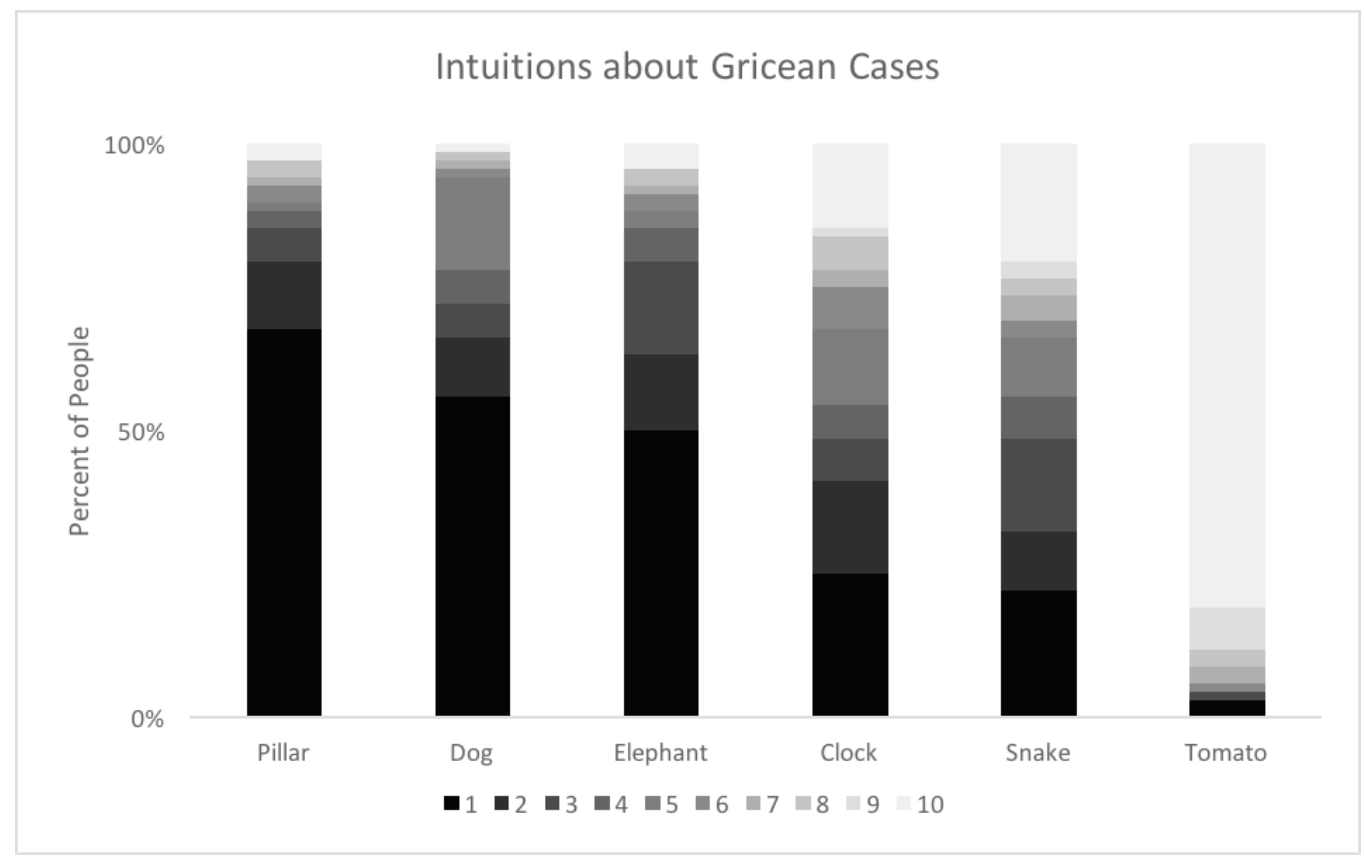

Figure 1.

The finding that Elephant is between the blocker and non-blocker cases is descriptively surprising and will be discussed in the next section. (However, as will be seen, Elephant was not statistically different from Pillar.)

In Figure 1, the bars for the blocker cases are strikingly similar and suggest greater disagreement than the bars for the non-blocker cases, which are also quite similar. The same similarities do not appear across explicit and nonexplicit cases. This suggests that participants may be more strongly affected by whether a case includes a blocker component than a component that makes the lack of a counterfactual dependence explicit. To compare these responses statistically, we thought to use a repeated-measures ANOVA but did not, because the scores are not normally distributed. The distribution problem is particularly pronounced for the Clock and Snake cases. Participants' responses to these cases indicate mass between-subject disagreement. The mode was 1 for both cases, with $25 \%$ choosing this for the Clock case and $22 \%$ for the Snake case. However, the next most frequently chosen response for both cases was 10, with 15\% choosing this for Clock and 21\% for Snake. Noting this, we chose to use Friedman's test to compare responses, a non-parametric test similar to a repeated-measures ANOVA.

The results of the Friedman's test were significant, indicating some difference between the cases, $X^{2}=187.60, p<0.001$. All 15 post hoc comparisons were 
then conducted. The Bonferroni correction was applied to interpret the results. 5 To be deemed significant the unadjusted $p$-value obtained had to be less than 0.003333 continuing. The unadjusted $p$-values are reported in the text. Tomato was significantly higher than all the other cases $\left(p^{\prime}\right.$ s $\left.<0.001\right)$. Neither of the blocker cases were different from Elephant $\left(p^{\prime} s>0.12\right)$. However, regarding the nonblocker cases, although Clock was not different from Elephant $(p=0.01)$, Snake was different from Elephant $(p<0.001)$.

The remaining post hoc comparisons revealed a main effect of blocker. A main effect is an effect of an independent variable on a dependent variable across the levels of another independent variable. In the present experiment, there is an effect of blocker (an independent variable) on participants' agreement (a dependent variable) across the two levels of explicit (another independent variable). A main effect of blocker is obtained because there was a significant difference in participants' responses across both the explicit cases (participants agreed less with Dog than Clock, $p=0.003$ ) and non-explicit cases (participants agreed less with Pillar than Snake, $p<0.001$ ).

A main effect of explicit was not obtained. There was not a significant difference in participants' responses across both the blocker cases (participants' responses to Dog and Pillar did not differ, $p=0.31$ ) and non-blocker cases (participants' responses to Clock and Snake did not differ, $p=0.18$ ). For completeness, the remaining post hoc comparisons are that the difference between Pillar and Clock was significant $(p<0.001)$, and the difference between Dog and Snake was significant $(p<0.001)$.

\section{Discussion}

We shall discuss our results for the blocker/non-blocker cases, the explicit/nonexplicit cases, and the Elephant case. Then, we will look at what our results mean for the view that the causal condition on perception is a conceptual truth. We argue that our results are problematic for the view. Next, we will look at some alternative explanations for our results and defuse them. We then will examine a number of objections against our methodology. Finally, we end by offering some interesting directions for future research.

Blocker/Non-Blocker. The strong disagreement elicited by the blocker cases shows that the folk strongly judge that there is a no blocker condition on perception. Can we say that the folk strongly judge there to be a causal condition

5. The Bonferroni correction is as follows: 0.05 divided by the number of tests. Here the number of post hoc comparisons was 15 , so $0.05 / 15=0.003333$ continuing. 
(assuming that this is what the Gricean cases establish)? No. Here is why. The non-blocker cases elicited much more agreement than we thought they would and were significantly different from the blocker cases. Although the means and medians were below 5 for the non-blocker cases, there was mass disagreement regarding how they should be rated. The modes were 1 for both non-blocker cases, but the second most common response was a 10. If the folk judge that there is a causal condition on perception, they presumably should disagree with both the blocker and non-blocker cases. Thus, our results do not seem to support the view that the folk strongly judge that there is a causal condition. Given our results, it would be wrong to say that the folk disagree with the non-blocker cases. We can at most say that a large percentage of people disagree with the non-blocker cases, keeping in mind that a sizable percentage agree. It is a no blocker condition, not a causal condition, to which folk intuitions strongly point.

A clarification is called for regarding what we mean by a 'no blocker condition.' A no blocker condition is simply this: necessarily, if a subject sees an object, then there is no physical thing blocking or in the way of the subject's line of sight. This condition is much weaker than the causal condition. The causal condition is as follows: necessarily, if a subject sees an object, that object causally affects the subject. In any situation in which the no blocker condition fails, the causal condition will presumably also fail, but the opposite is false: there can be situations in which the causal condition fails but the no blocker condition does not, namely the situations described in Clock and Snake. Thus, to replace the causal condition with the no blocker condition would be to increase the number of situations in which people can be said to 'see.' Given this clarification, our results suggest that the intuitions about when one 'sees' of many non-philosophers are more liberal than those of philosophers. ${ }^{6}$

Explicit/Non-explicit. There was no main effect of explicit. That is, whether or not a case explicitly stated that there was no counterfactual dependence did not affect participants' responses. Keeping in mind that we should be cautious of making an inference of no difference from a negative result (Machery 2012; Hoenig \& Heisey 2001), we can think of two possible explanations of why it might be that not explicitly mentioning a counterfactual dependence has no effect. First, the lack of an effect could be due to participants inferring the lack of counterfactual dependence even in cases where it is not explicit. Alternatively, the lack of an effect could be due to participants not judging a counterfactual dependence

6. A no blocker condition may seem to imply that we do not see the person, in the relevant sense of 'see,' who is on the other side of, for example, a video call. However, whether this is true in fact depends on what the correct way of understanding video calls is. Perhaps, video calls are transparent to one's line of sight (like a pane of glass), so that we see through the video call to the person to whom we are speaking, directly. 
to be that important. Philosophers think counterfactual dependence is at least implied by the causal condition. So, participants may judge that a counterfactual dependence is not that important, because they judge that the causal condition is not that important. As our evidence from the blocker/non-blocker cases suggests that participants do not strongly endorse a causal condition, we suspect that the second explanation has something to do with our results. However, we cannot rule out the first stated possibility. Further research would be required to fully understand how important counterfactual dependence is to the folk. Our present study, though, focuses on folk intuitions regarding the causal condition more specifically.

Elephant. The finding that the disagreement with the blocker cases was descriptively higher than the disagreement with Elephant was surprising. Although the difference was not significant, we might speculate anyway as to what might have been going on. One idea is that some participants were influenced by the description of the Elephant case as being one in which 'You are looking at a tomato... . Perhaps some of our participants took this to imply that the tomato is thereby seen, and so implicitly treated Elephant as a case of illusion (rather than as a case of hallucination) in which the tomato is seen (incorrectly) as an elephant (because of the drug taken). This idea is consistent with the findings of Fischer and Engelhardt (2016) that statements of the form 'S is aware of an $\mathrm{F}^{\prime}$ and 'S perceives an $\mathrm{F}^{\prime}$ are strongly stereotypically associated with the ascription to $\mathrm{S}$ of an epistemic achievement (such that $\mathrm{S}$ knows that it is an $\mathrm{F}$ that she is aware of/perceives), and this strong stereotypical association supports an automatic inference from the verbs 'to be aware of' and 'to perceive' to an epistemic achievement (e.g., successfully seeing the tomato in our Elephant case). ${ }^{7}$ Further investigation would be needed to confirm our proposed explanation of the Elephant case, although settling this matter does not bear on our interpretation of the results for Pillar, Dog, Snake, and Clock. The locution 'You are looking at ...' was not used in these cases.

Conceptual truth. If we are interpreting our results correctly, what should we conclude about the status of the claim that the causal theory of perception is a conceptual truth? We interpret our results to show that it is a no blocker condition to which folk intuitions strongly point rather than a causal condition. If this is correct, then, as we will argue in this section, our results put pressure on the claim that it is a conceptual truth that veridical perceptual

7. Fischer and Engelhardt (2016) do not explicitly consider statements of the form 'S looks at X,' although it is plausible that 'looks at' will behave in a similar way to 'aware of.' They also found that locutions of the form ' $X$ looks $F$ to $S^{\prime}$ are stereotypically associated with the ascription to $S$ of an inclination to believe that $X$ is $F$, which suggests that 'looking at' should at least support automatic inferences to doxastic ascriptions about $X$ to $S$. 
experiences are causally dependent on the subject's environment. We look at what our results mean under restricted and more liberal notions of 'conceptual truth.'

Exactly what it takes for something to be a conceptual truth is controversial. One popular view, which is operative in the debate we are considering, is that it involves something like being 'relatively immediately acknowledgeable by any person, whatever their education, who can count as having the concept in question' (Snowdon 1980: 176). On this way of understanding 'conceptual truth,' it is not clear given our results that the causal theory of perception is a conceptual truth. ${ }^{8}$ Our results are that a significant number of participants were quite content holding that they would see the actual object in non-blocker cases. Amazingly, 21\% of our participants strongly agreed, choosing a response of 10, that they would see the actual snake in Snake and 15\% that they would see the actual clock in Clock. (Given that there is no main effect of explicit, it is not clear that the counterfactual dependence of our experience on the environment is a conceptual requirement either, but we will not focus on this fact. We are mostly concerned with the causal condition.)

If the causal theory of perception is not a conceptual truth in this sense, then what is it? It would presumably be a widely accepted empirical, or more generally theoretical, belief about perception. That is, it would be like claims such as 'whales are mammals' and 'water is $\mathrm{H}_{2} \mathrm{O}$.' These are claims that most modern people accept, even though it is possible to possess the concepts of WHALE and WATER and either be agnostic about, or even deny (Vandewall 2007) their truth (for a similar suggestion, see Snowdon 1980: 176). 9

According to this empirical/theoretical belief explanation, the bimodal responses to the non-blocker cases would reflect the fact that not all participants appealed to these widely held empirical, or more generally theoretical, beliefs when responding to Snake and Clock. One objection to this explanation is that all of our participants were educated to university level, and so it would seem reasonable to believe that they should all share the relevant empirical, or more generally theoretical, beliefs about perception, just as we would expect the majority of (if not all) undergraduate students to believe that whales are mammals

8. Views according to which perceptual experiences depend non-causally on the environment typically require that experiences exhibit counterfactual dependence on the environment. So, our results also put pressure on one common line of resistance to the causal theory of perception: that responses to Gricean cases fail to establish that we implicitly believe that experiences causally depend on our environment, as opposed to depending on the environment in some other noncausal way (White 1961; Hyman 1992; Roessler 2011).

9. Snowdon (1980) does not distinguish between widely accepted empirical and widely accepted theoretical beliefs about perception. However, there may be important differences between these kinds of beliefs, depending on exactly where the boundary between the empirical and the theoretical is drawn. 
and that water is $\mathrm{H}_{2} \mathrm{O}$. However, in reply, it might be suggested that the relevant empirical, or more generally theoretical, beliefs about perception are not as widespread as the relevant views about whales and water. Further, participants could hold the relevant empirical or theoretical beliefs without appealing to them when responding to the cases. ${ }^{10}$

Not every way of understanding what it is for something to be a 'conceptual truth' (or perhaps more generally, a core common sense belief) draws a sharp distinction between conceptual and empirical or theoretical beliefs. One might therefore grant that the causal condition is not a conceptual truth in the restricted sense given to it by Snowdon and others but insist that, in a broader sense, it does represent a conceptual truth. According to proponents of the so-called 'Canberra Plan,' for instance, the role of conceptual analysis in philosophical theorizing is to identify a set of platitudes relating to something that we want to give a philosophical account of. Intuitions about cases are supposed to help us to identify the relevant platitudes; these platitudes in turn provide an implicit theory of the thing in question, and the thing in question is then identified with whatever turns out to make the theory true (e.g., Jackson 1998; Braddon-Mitchell \& Nola 2009). There are different views of what these platitudes can include. Although they can be restricted to what would traditionally be thought of as conceptual or analytic truths, they need not be: they can also include platitudes that represent empirical or theoretical beliefs (see, e.g., Nolan 2009).

However, even if the platitudes are not narrowly restricted to analytic truths, they will, at least when providing philosophical analyses of folk concepts, like perception, color, and the mental, standardly be restricted to claims that are widely accepted by ordinary users of the relevant concepts. The reason for this is that conceptual analysis, on this view, is intended to 'fix the subject' of philosophical investigation. Where philosophical investigation concerns something that we have folk concepts of, or folk theories about, we are typically interested in that thing as we ordinary conceive of it. If we were not, we would risk simply changing the subject and providing a philosophical account of something else (see, e.g., Jackson 1998). So, even given a more liberal understanding of 'conceptual truth,' such as that which might be employed by someone implementing the Canberra plan, the present findings put pressure on the claim that the causal theory of perception is a conceptual truth. Although the causal condition is

10. Winer et al. (2002) have shown that it is possible to elicit (seemingly) extramissionist intuitions about perception, according to which something leaves the eye when we perceive, in a sizeable proportion of subjects, even amongst university students who have just completed an introductory course on vision science. Winer et al.'s diagnosis is that extramissionist responses are widespread and resistant to training, because they reflect the phenomenology of visual experience. It might be suggested that agreement with non-blocker cases similarly reflects a way of thinking about perception grounded in the phenomenology of experience. 
widely accepted, there is a large minority of subjects who seem to reject it. Thus, it would not seem that Canberra planners can consider the causal condition to be a platitude about perception for the purposes of enacting the Canberra plan.

It might be argued that the claim that the causal theory of perception is a conceptual truth is not undermined by the finding that there is mass betweensubject disagreement with non-blocker cases, if it is allowed that some conceptual truths are more difficult to grasp than others. So, for instance, it might be suggested that 'all unmarried men are unmarried men' is easier to grasp than 'all bachelors are unmarried men' (assuming that this is a conceptual truth). By comparison, it might be suggested that blocker cases are easier to grasp than non-blocker cases, and that those who agree with non-blocker cases are simply mistaken in their judgments. One possible explanation for why participants find non-blocker cases more conceptually difficult than blocker cases could be that they are further removed from the types of perceptual situations that most people are likely to encounter.

The use of comprehension questions to assess participants' understanding of the cases give some reason for questioning this argument. Moreover, participants did not seem to struggle more with the comprehension items for the non-blockers than the blockers. ${ }^{11}$ This said, the comprehension questions alone do not provide a decisive reason for rejecting the relevant concern: the comprehension questions do not directly test the kind of conceptual understanding that participants who agreed with non-blocker cases are being said to lack. Regardless, the specific suggestion that subjects might find non-blocker cases conceptually more difficult because they are further removed from reality is not obviously true. Dog and Snake seem about equally far removed from the types of perceptual situations that most people are likely to encounter. Virtual reality headsets are still rare and most people have never used them. We have no way of knowing the prevalence of drug use amongst our participants, but a drug induced hallucination is not that far removed from a vivid dream, which many will have experienced at least once. Thus, it is at best unclear that the blocker cases would be easier to grasp than the non-blocker cases. In fact, given that the blocker cases are more involved, one might think that if anything, the blocker cases are harder to understand than the non-blocker cases, not the opposite.

Ultimately, whether the idea that non-blocker cases are more difficult can be used to salvage the claim that the causal condition is a conceptual truth depends on wider considerations about the nature of conceptual truths. The idea in question would at least need to reject the kind of characterization of 'conceptual truth' suggested by Snowdon, according to which a conceptual truth is

11. The number of participants who accurately answered all three comprehension items for each case are as follows: Dog 107, Pillar 110, Clock 111, and Snake 119. The Chi-squared test indicated that there were no significant differences $(X(3)=3.49, p=0.32)$. 
"relatively immediately acknowledgeable by any person, whatever their education, who can count as having the concept in question" (Snowdon 1980: 176). At this point, the challenge for our opponents is to provide a substantive characterization of 'conceptual truth' that allows for the non-arbitrary distinguishing of those propositions that are conceptual truths from those propositions that are either non-conceptual truths, or not truths at all. Whether this is possible is outside the present article's scope.

Alternative Explanations. We interpret our results to show that it is a no blocker condition to which folk intuitions strongly point rather than a causal condition. Is this the correct interpretation of our results? One alternative explanation is that the between-subject disagreement about non-blocker cases reflects differing ways of understanding perceptual verbs like 'see.' Perceptual verbs like 'see' have object-entailing uses, such that we are only prepared to say that someone sees, for example, a red tomato, if the red tomato is actually there. Used in this way, 'see' is what Ryle calls a 'success verb' (2000). However, perceptual verbs also have uses that are not object-entailing, as when we say of someone suffering from delirium tremens that they see pink rats. ${ }^{12}$ It might be suggested that when people agree with the non-blocker cases, Clock and Snake, that they are understanding 'see' in a non-object entailing way. Moreover, it might be suggested that this way of understanding 'see' highlights an innocuous ambiguity in uses of perceptual verbs that does not contradict the causal condition. One problem with this alternative explanation, however, is that we included the word 'actual' in the blocker and non-blocker statements (with which we asked participants to indicate their agreement), so that the statements read, for example, 'you see the actual snake.' Thus, the structure of these statements hinders 'see' as being understood as non-object entailing.

It might be replied that there is a phenomenal reading of 'see the actual snake' according to which it means something like, 'have an experience like that of seeing the snake that actually is in front of you' (cf. Fischer \& Engelhardt, in press). If this reply is correct, it would be problematic for us, because the use of the word 'actual' in the statements would not guarantee that our participants understood 'see' in an object-entailing way. For this objection to be successful, some explanation would be needed for why 'see the actual ...' would be understood by our participants differently in the blocker and non-blocker statements. One suggestion might run as follows: non-blocker statements are read as employing a phenomenal, non-object entailing sense of 'see,' because non-blockers are implicitly treated as cases of hallucination; whereas, blocker statements are read as employing an object-entailing sense of 'see,' because blockers are implicitly

12. Compare this to factive vs. non-factive uses of the term 'knows.' For discussion of a related objection to there being differences in intuitions about Gettier cases, see Weinberg, Nichols, and Stich (2001). 
treated as cases of illusion, in which an object (e.g., a dog or a pillar) is seen as occupying a different location to the location that it in fact occupies. ${ }^{13}$

We are sceptical about whether there is an available phenomenal reading of 'see the actual ...' and if there is, whether it is sufficiently natural to explain the results that we have found. Moreover, the suggestion in question leaves some important things unexplained. First, it is unclear why non-blocker cases would be interpreted as hallucinations and blocker cases not. Second, it is unclear why non-blocker cases being treated as hallucination cases would result in non-blocker statements being understood as employing a phenomenal sense of 'see.' Further development of the suggestion in question would be interesting, but is outside the scope of our paper. Ultimately, how people understand the statements is an empirical matter that requires further investigation.

A second alternative explanation of our findings is that there is a widespread understanding of the disabling conditions for perception (those factors which 'block' perception) but a lack of consensus about the enabling conditions for perception (those factors which make perception possible). ${ }^{14}$ In particular, it might be thought that some are treating the scientist (who is stimulating the subject's cortex in Clock) and the drug (which is making it seem as if there is a snake in Snake) as enabling conditions of the causal process by which a veridical experience is produced. As such, it might be suggested that the mass between-subject disagreement with Clock and Snake does not mean that the folk do not find a causal condition on perception intuitive. Rather, the disagreement just reflects a disagreement about what is required for the things that we perceive to cause our experiences. The difficulty with this response, however, is that both Clock and Snake are framed in a way that is intended to discourage this kind of reading: Snake and Clock by noting that the match between the experience and the environment is coincidental ('as it happens'); Clock also by explicitly noting the lack of a counterfactual dependence of the experience on the world. This suggests that those participants who agreed with Clock and Snake were not implicitly thinking of the scientist and the drug as part of a genuine, albeit non-standard, causal chain.

Objections to methodology. We shall now turn to considering a number of objections to our experiment and its methodology. We will avoid meta-philosophical objections about the value of intuitions in philosophy (Ladyman \& Ross 2007; Dorr 2010; Maclaurin \& Dyke 2012). These debates are outside the scope of this article. As we said, we are concerned with objections to the methodology of our experiment only. We will look at three objections of this kind: an objection to the

13. We would like to thank an anonymous referee for this suggestion and for encouraging us to think about the general line of argument being discussed.

14. For further discussion of 'disabling' and 'enabling' conditions of perception, see Richardson (2015). 
effect that we used a repeated-measures design; an objection to the effect that we dropped many participants' responses; and an objection to the effect that our sample was largely university students. We respond to these objections in turn.

The first objection is that we used a repeated-measures design. The concern here is that this design allows for order to affect the results, for example, whether participants got Pillar first or second, Clock first or second, and so on. We were aware of such concerns. Because of practical issues with getting enough participants to look at order for six cases, we sought to address this concern via randomizing the order cases were presented to participants. It is true that even with randomization that order can affect the results. However, looking at participants' responses grouped according to order, we see no signs that order had an impact. Most importantly, Pillar and Dog are disagreed with more, descriptively speaking, than Clock and Snake regardless of order. Thus, while there are certainly not enough participants in each order to statistically test for order effects, descriptively, there is no clear reason to worry. This said, future research could choose to investigate possible order effects. Anyone interested in this should consider reducing the number of cases they examine. Note that with 6 cases there were 720 orders while with 4 cases there would be 24 orders, so examining order effects becomes untenable without a large participant database very quickly.

The second objection is that we dropped almost half of our participants. In reply, normally, the concern with excluding so many participants is that doing so introduces a selection bias that may skew the results. In our case, the selection bias introduced was intended: to bias the results towards those who understood the cases. As we are interested in participants' responses to the six cases as presented, it is important that participants' responses are to the cases as presented. Thus, it is important to exclude participants who failed any comprehension questions. If they did not understand the cases, they could not respond to them as presented, as opposed to their incorrect interpretations of them. It is unfortunate that so many failed to get all the comprehension questions correct. This is plausibly due to participants rushing through the experiment and so not paying attention. This is always a problem with online surveys and why comprehension questions must be used.

A final objection is that our participants were largely university students in the UK. The worry is that our results might not generalize to the population at large. There is no clear reason to suspect that our sample explains our results. We dropped participants who had university experience with philosophy, so the worry would have to be that non-philosophy university students are different from the population at large. For this worry to undermine our main arguments in this paper, what would need to be shown is that the non-causal condition intuitions of the university educated are somehow an artifact of their university- 
level education. However, that just does not sound like a very plausible explanation. If anything, one might expect that the number of people who did not accept the causal condition would rise when looking at the general population. By contrast, it seems much more plausible to suppose that causal condition intuitions are the result of a general scientific education.

Regardless, when criticizing our results for being based on university students, it is important to be aware of the advantages of using university students in addition to the disadvantages. For one, we knew our participants would all have a certain degree of education. So, we could be sure that many would have the skills required to read and understand the cases presented. We could not ensure that members of the general public would have the skills required. It is plausible that the percent who failed our comprehension items would have been even higher were we to have used the general public. This said, this study is the first of many experiments that need to be conducted to produce a solid body of evidence regarding people's intuitions about the causal theory of perception. This study should be seen as encouraging, not discouraging, further research into the subject.

Future research. We have discussed in passing various avenues for further research already. However, we wish to conclude by mentioning three possible directions for further research we think are especially interesting. As we find mass between-subject disagreement regarding the non-blocker cases, an obvious future research project is to try to ascertain what explains the disagreement. In the present article, we take the stance that the disagreement is explained by participants really having different intuitions. This we point out is a problem for the claim that the causal theory of perception is a conceptual truth. In the section 'Alternative explanations,' we looked at two possible alternative explanations and found neither particularly convincing. However, we welcome further research into alternative explanations. If our findings could be explained away, then that would be interesting.

A second possible direction for future research is to look into whether the difference we found between blocker and non-blocker cases is consistent across all the senses. There is some evidence that people recognize a metaphysical distinction between color and sound on the one hand and gustatory taste on the other (Roberts \& Schmidtke 2016), where participants judge the former to be more anti-relational and the latter to be more relational. Could views about such metaphysical differences impact participants' responses to blocker and non-blocker cases? It would be especially interesting if people recognized a causal condition for some perceptible properties (e.g., tastes) but not others (e.g., colors). A further related question would be whether cases concerning senses that are thought to be transparent by many philosophers (e.g., vision) invoke different folk intu- 
itions regarding the causal condition than those senses less commonly thought to be transparent (e.g., smell).

The third possible direction for future research that we wish to discuss is to look at cross-cultural divergence. (Our data does not allow for us to comment on cross-cultural differences, as our sample was mainly composed of native English speakers.) It is interesting to note that there is a structural similarity between Gricean cases and Gettier cases. What might this mean? In Gricean cases, a subject's experience represents the world correctly but does not count as perception, while in Gettier cases a subject's belief represents the world truly but does not count as knowledge. There is some evidence that Gettier cases exhibit cross-cultural variation (Weinberg, Nichols, \& Stich, 2001). Thus, the structural similarity might mean that we should expect cross-cultural variation in Gricean cases too.

Further research has cast doubt on the claim that folk intuitions about Gettier cases really exhibit cross-cultural variation (Nagel, Juan, \& Mar 2013), and so it might turn out that no significant cross-cultural variation would be found for Gricean cases either. This in itself would be an interesting result. However, we should not assume that no cross-cultural variation would be found for Gricean cases, because at least some folk intuitions do seem to exhibit cross-cultural differences: for instance, Machery, Mallon, Nichols, and Stich's (2004) finding that there is significant cross-cultural divergence between Western and East Asian peoples' intuitions about descriptive theories of names seems robust. Further, there is a particularly interesting cross-cultural question relating to our experiment: is the mass between-subject disagreement about non-blocker cases consistent between cultures? If so, this would suggest a widespread fundamental disagreement about perception.

\section{Acknowledgements}

We would like to thank the University of York's Mind and Reason group for discussion of the survey design and how to best interpret possible results. We are also grateful to two anonymous referees who did a fantastic job.

\section{References}

Allen, Keith (2016). A Nä̈ve Realist Theory of Color. Oxford University Press.

Braddon-Mitchell, David and Robert Nola (2009). Introducing the Canberra Plan. In David Braddon-Mitchell and Robert Nola (Eds.), Conceptual Analysis and Philosophical Naturalism (1-20). MIT Press. 
Cohen, Jonathan and Shaun Nichols (2010). Colours, Colour Relationalism and the Deliverances of Introspection. Analysis, 70(2), 218-228. https://doi.org/10.1093/analys/ anp161

Dorr, Cian (2010). Review of James Ladyman and Don Ross, Every Thing Must Go: Metaphysics Naturalized. Notre Dame Philosophical Reviews. Retrieved from http:// ndpr.nd.edu/news/24377-every-thing-must-go-metaphysics-naturalized/

Grice, H. Paul (1961). The Causal Theory of Perception. Proceedings of the Aristotelian Society, supplementary volume, 35, 121-152. https://doi.org/10.1093/aristoteliansupp/35.1.121

Fischer, Eugen and Paul E. Engelhardt (2016). Intuitions' Linguistic Sources: Stereotypes, Intuitions and Illusions. Mind and Language, 31(1), 67-103. https://doi.org/10.1111/ mila.12095

Fischer, Eugen. and Paul E. Engelhardt (in press). Stereotypical Inferences: Philosophical Relevance and Psycholinguistic Toolkit. Ratio.

Hoenig, John M. and Dennis M. Heisey (2001). The Abuse of Power: The Pervasive Fallacy of Power Calculations for Data Analysis. Statistical Practice, 55(1), 1-6. https:// doi.org/10.1198/000313001300339897

Hyman, John (1992). The Casual Theory of Perception. The Philosophical Quarterly, 42(168), 277-296. https://doi.org/10.2307/2219681

Jackson, Frank (1998). From Metaphysics to Ethics. Clarendon Press.

Johnston, Mark (1992). How to Speak of the Colors. Philosophical Studies, 68(3), 221-263. https://doi.org/10.1007/BF00694847

Ladyman, James and Don Ross (2007). Every Thing Must Go: Metaphysics Naturalized. Oxford University Press.

Lewis, David (1980). Veridical Hallucination and Prosthetic Vision. Australasian Journal of Philosophy, 58(3), 239-249. https://doi.org/10.1080/00048408012341251

Machery, Edouard, Ron Mallon, Shaun Nichols, and Stephen P. Stich (2004). Semantics, Cross-Cultural Style. Cognition, 92(3), 1-12. https://doi.org/10.1016/j.cognition.2003.10.003

Machery, Edouard (2012). Power and Negative Results. Philosophy of Science, 79(5), 8o8-82o. https://doi.org/10.1086/667877

Maclaurin, James and Heather Dyke (2012). What Is Analytic Metaphysics For? Australasian Journal of Philosophy, 9o(2), 291-306. https://doi.org/10.1080/00048402.2011.587 439

Nagel, Jennifer, Valerie S. Juan, and Richard A. Mar (2013). Lay Denial of Knowledge for Justified True Beliefs. Cognition, 129(3), 652-661. https://doi.org/10.1016/j.cognition.2013.02.008

Nolan, Daniel (2009). Platitudes and Metaphysics. In David Braddon-Mitchell and Robert Nola (Eds.), Conceptual Analysis and Philosophical Naturalism (267-300). MIT Press.

Richardson, Louise (2015). Perceptual Activity and Bodily Awareness. Proceedings of the Aristotelian Society, 115(2pt.2), 147-165. https://doi.org/10.1111/j.1467-9264.2015.00389.x

Roberts, Pendaran, James Andow, and Kelly Schmidtke (2014). Colour Relationalism and the Real Deliverances of Introspection. Erkenntnis, 79 (5), 1173 - 1189. https:// doi.org/10.1007/s10670-014-9600-6

Roberts, Pendaran and Kelly Schmidtke (2016). Folk Core Beliefs about Color. Poster presented at Experimental Philosophy as Applied Philosophy: The 2016 Ratio Conference $\& 7^{\text {th }}$ Annual Conference of Experimental Philosophy Group UK, University of Reading, UK. 
Roberts, Pendaran and Kelly Schmidtke (2016). Relationalism about Perceptible Properties and the Principle of Charity. Synthese, 193(9), 2779-2803. https://doi.org/10.1007/ s11229-015-0886-y

Roessler, Johannes (2011). Causation in Commonsense Realism. In Johannes Roessler, Hemdat Lerman, and Naomi Eilan (Eds.), Perception, Causation, and Objectivity (103-120). Oxford University Press. https://doi.org/10.1093/acprof:o so/9780199692040.003.0008

Ryle, Gilbert (2000). The Concept of Mind (2nd ed.). Hutchinson.

Snowdon, Paul (1980). Perception, Vision, and Causation. Proceedings of the Aristotelian Society, 81, 175-192. https://doi.org/10.1093/aristotelian/81.1.175

Strawson, Peter F. (1979). Perception and its Objects. In G.F. MacDonald (Ed.), Perception and Identity: Essays Presented to A. J. Ayer (41-6o). Macmillan. https://doi. org/10.1007/978-1-349-04862-5_2

Strawson, Peter F. (1992). Analysis and Metaphysics: An Introduction to Philosophy. Oxford University Press. https://doi.org/10.1093/acprof:oso/9780198751182.001.0001

Weinberg, Jonathan M., Shuan Nichols, and Stephen Stich (2001). Normativity and Epistemic Intuitions. Philosophical Topics, 29(1-2), 429-460. https://doi.org/10.5840/philtopics2001291/217

Winer, Gerald A., Jane E. Cottrell, Virginia Gregg, Jody S. Fournier, and Lori A. Bica (2002). Fundamentally Misunderstanding Visual Perception: Adults' Beliefs in Visual Emissions. American Psychologist, 57(6-7), 417-424. https://doi.org/10.1037/0003066X.57.6-7.417

White, Alan R. (1961). The Causal Theory of Perception. Proceedings of the Aristotelian Society, 35, 153-168.

Woodward, James (2011). Causal Perception and Causal Cognition. In Johannes Roessler, Hemdat Lerman, and Naomi Eilan (Eds.), Perception, Causation, and Objectivity (229-263). Oxford University Press. https://doi.org/10.1093/acprof:o so/9780199692040.003.0014

Vandewall, Holly (2007). Why Water is Not $\mathrm{H}_{2} \mathrm{O}$ and Other Critiques of Essentialist Ontology from the Philosophy of Chemistry. Philosophy of Science, 74(5), 906-919. https://doi.org/10.1086/525632 


\section{Appendix}
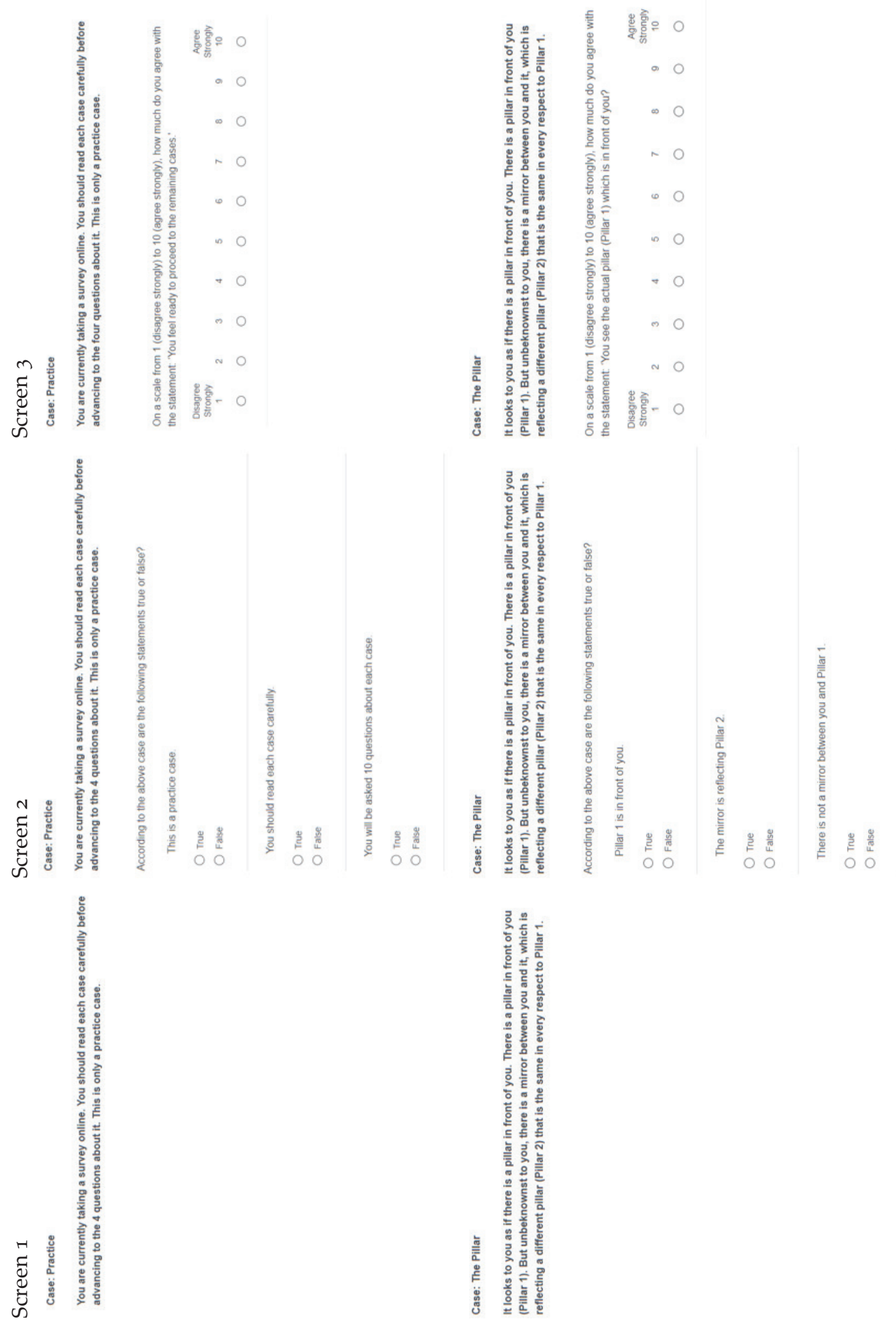

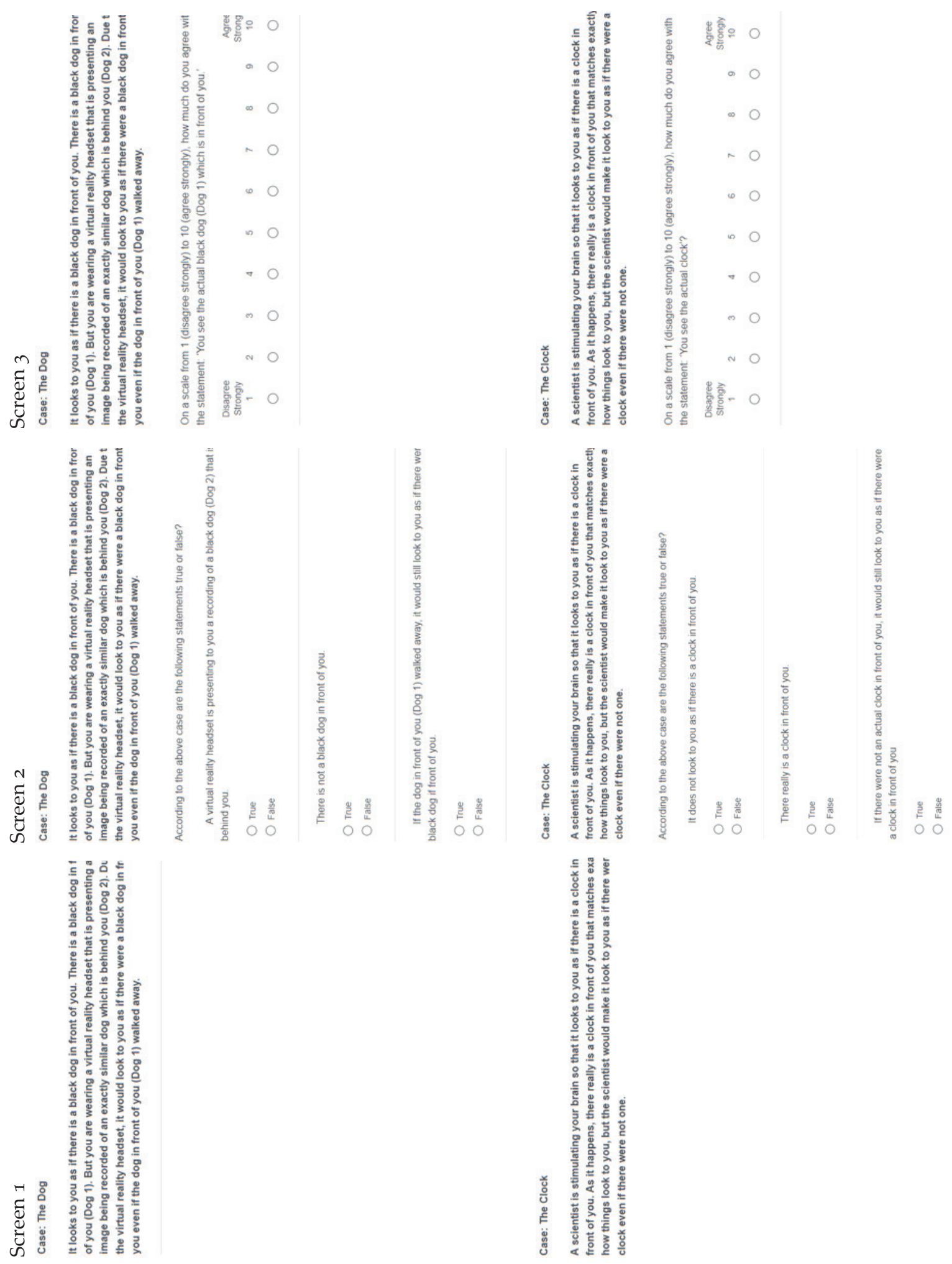

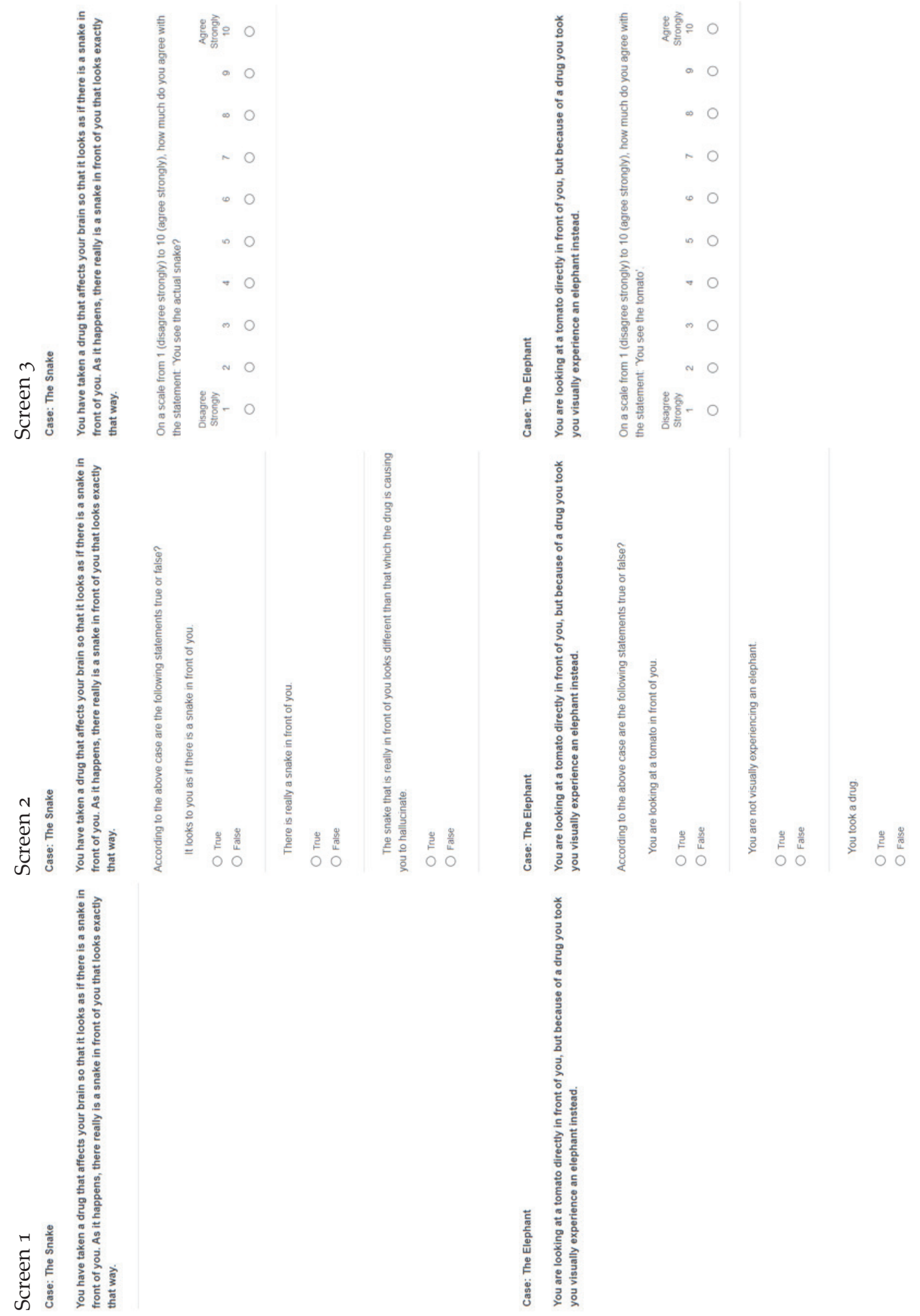

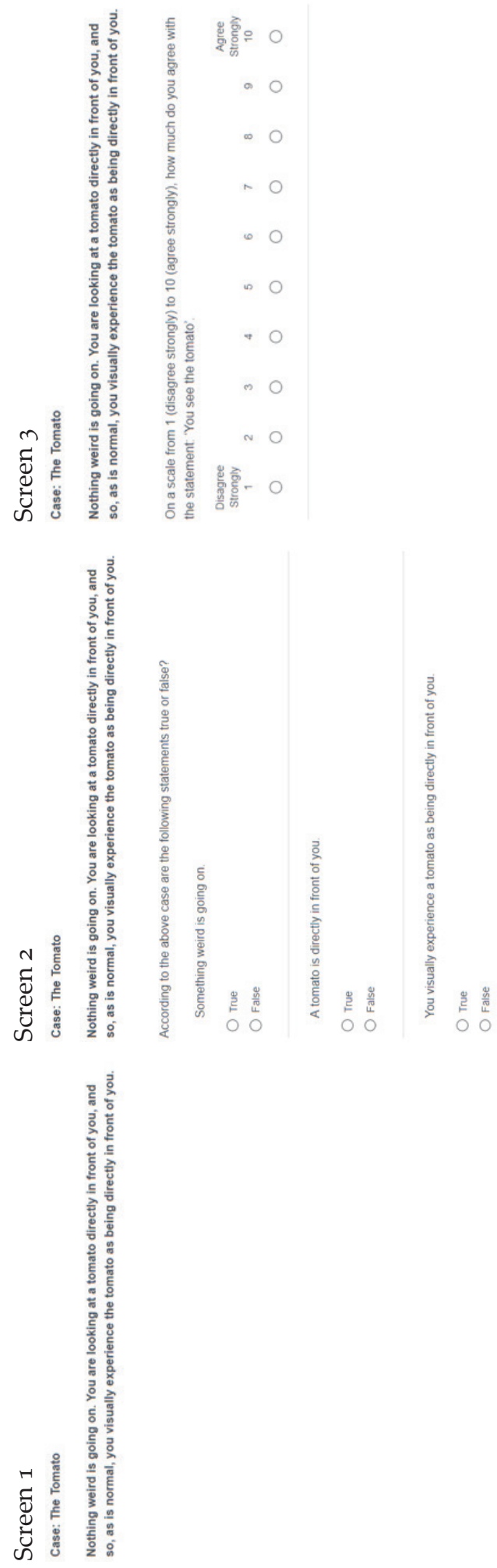